\title{
Nuevos enfoques para comprender el desarrollo de los conceptos biológicos en niños pequeños
}

\section{New approaches to understanding the development of biological concepts in young children}

\author{
Zayba GhazAli $^{1}$ \\ zghazali@ioe.ac.uk \\ ANDREW TOLMIE \\ a.tolmie@ioe.ac.uk \\ Universidad de Londres, Reino Unido
}

\begin{abstract}
:
This paper outlines the development of a new methodology to assess young children's (aged 4-11) ideas about biological phenomena in an effort to understand conceptual development across the primary age range. Presently, curricular design is an activity that rests on some fundamental assumptions about the organisation of knowledge and development of understanding. For instance, the National Curriculum for England is organised in a manner that assumes sequential learning of scientific concepts so that generalised understanding can be developed on the basis of earlier concepts. However there is a distinct lack of any systematic literature on the processes behind conceptual development, which have often shown children's learning to be piecemeal and unlikely to progress in such a straight-forward and linear fashion, contrary to earlier theorising
\end{abstract}

1 Dirección para correspondencia (Correspondence address):

Zayba Ghazali. Institute of Education. University of London. 20 Bedford Way. London WC1H 0AL (United Kingdom). 
Nuevos enfoques para comprender el desarrollo de los conceptos biológicos en niños pequeños

Zayba Ghazali y Andrew Tolmie

cuencial y lineal, en contra de la teorización anterior (e.g. Piaget, 1972). Existe un cuerpo de trabajo, como las ideas iniciales de la herencia, que se fundamenta en paradigmas muy limitados y que han dado lugar a una visión muy distorsionada de las capacidades de los niños. Otros trabajos destacan el hecho de que los niños pequeños comienzan la escuela con un conocimiento previo existente $y$, a menudo tienen ideas erróneas que son altamente resistentes al cambio (Driver, Guesne y Tiberghien, 1985). Cómo es organizado el esquema cognitivo, no puede ser totalmente comprendido sin explorar previamente los procesos que están detrás de el cambio conceptual y sobre todo las formas en las que los conceptos relacionados están interconectados de una forma más coordinada. Esto es algo que raramente ha sido foco de la investigación psicológica. Nuevas perspectivas para evaluar el desarrollo conceptual en biología son presentadas en el presente trabajo en un esfuerzo por redirigir el asunto.

\section{Palabras clave:}

Biología; desarrollo conceptual; aprendizaje de la ciencia; Currículo; Ciencia en Primaria. (e.g. Piaget, 1972). Where there is any body of work, such as on early ideas of inheritance, it is based on highly constrained paradigms that have arguably led to a distorted view of children's capabilities. Other work also highlights the fact that young children start school with existing prior knowledge and often hold misconceptions that are highly resistant to change (Driver, Guesne \& Tiberghien, 1985). How cognitive schemata are organised cannot be fully understood without first exploring the processes behind conceptual change and above all the ways in which related concepts are interlinked in more coordinated fashion. This is something that has rarely been the focus of psychological investigation. New approaches to assessing conceptual development in biology are presented in an effort to redress this.

\section{Key words:}

Biology; conceptual development; science learning; National Curriculum; primary science.

\section{Résumé:}

Le présent travail met en évidence le développement d'une nouvelle méthodologie pour évaluer les idées des enfants en Éducation Primaire (4-11 ans) sur des phénomènes biologiques, dans une tentative de comprendre le développement conceptuel tout au long de l'Éducation Primaire. Actuellement, la conception du curriculum est une activité qui repose sur quelques actions d'assumer l'organisation de la connaissance et le développement de la compréhension. De fait, le Curriculum National d'Angleterre est organisé de manière à assumer l'apprentissage séquentiel des concepts scientifiques, c'est pourquoi la compréhension généralisée peut être développée à partir des concepts préalables. Cependant, il existe une lacune dans la littérature sur les processus se trouvant derrière le développement conceptuel, qui ont démontré que l'apprentissage des enfants est fragmenté et qu'il est peu probable que celui-ci progresse dans la forme séquentielle et linéaire, à l'inverse de la théorisation antérieure (e.g.Piaget, 1972). Il existe un corpus de travail, comme les idées initiales de l'héritage qui se fondent sur des paradigmes très limités et qui ont donné lieu à une vision très défigurée des capacités des enfants. D'autres travaux mettent en évidence le fait que les jeunes enfants commencent l'école avec une connaissance préalable existante, et qu'ils ont souvent des idées erronées hautement résistantes au changement (Driver, Guesne y Tiberghien, 1985). Tel qu'est organisé le schéma cognitif, il ne peut pas être totalement compris sans une exploration préalable des processus qui se trouvent derrière le changement conceptuel et surtout sans une exploration des formes dont les concepts en lien sont interconnectés d'une façon plus coordonnée. Cela est une chose qui a rarement été au centre de la recherche en psychologie. De nouvelles perspectives pour évaluer le développement conceptuel en biologie sont présentées dans ce travail, dans un essai de reconduire le thème. 


\begin{abstract}
Mots clés:
Biologie; développement conceptuel; apprentissage de la science; Curriculum; Science en Primaire.
\end{abstract}

Fecha de recepción: 8-4-2014

Fecha de aceptación: 27-5-2014

\title{
Conceptual change and mental modelling
}

Curricular design is an activity that rests on some fundamental assumptions about the organisation of knowledge and development of understanding. Presently the National Curriculum (NC) for England is organised in a manner that assumes sequential learning of scientific concepts so that generalised understanding can be developed on the basis of earlier concepts. For instance in Key Sage 1 (KS1; age 4-7) children are taught the differences between living and non-living things and in Key Stage 2 (KS2; age 7-11) they are taught to establish causal effects and explain how living things and non-living things work (Department for Education; DfE, 2011). However even if it may seem intuitively reasonable, the assumption that seemingly complex concepts can only be understood after acquiring simpler ones is unwarranted due to an overwhelming lack of research. In the absence of such research, curricular design and organisation is based on little more than taxonomic structure and evident conceptual precedence typically seen from the viewpoint of the expert rather than of the learner, for whom emergent structures of knowledge may be organised in different ways. The problem is further accentuated by a lack of any systematic literature on the processes behind conceptual development, which has often shown children's learning to be piecemeal and unlikely to progress in such a straight-forward fashion, contrary to earlier theorising (e.g. Piaget, 1972). What is more, other work also highlights the fact that young children start school with existing prior knowledge and often hold misconceptions that are highly resistant to change (Driver, Guesne \& Tiberghien, 1985). The fact that children have been shown to have existing conceptual knowledge prior to any formal instruction, is something not accounted for by the current model of teaching in the United Kingdom. Thus questions into how the mind and cognitive schemata are organised cannot be fully addressed without first exploring the 
Nuevos enfoques para comprender el desarrollo de los conceptos biológicos en niños pequeños

Zayba Ghazali y Andrew Tolmie

potential processes behind conceptual change and above all the ways in which related concepts are coordinated and interlinked, something which has rarely been the focus of psychological investigation.

Progress in research has generally been restricted to the primary curriculum, for instance, the cognitive changes involved in literacy development are most well understood (e.g. Hulme \& Snowling, 2009) followed by numeracy and the early stages of arithmetic (e.g. Dowker \& Sigley, 2010). Understanding in these areas has been used to aid teaching practice, and yet comparable work has not been undertaken in the realm of science, with researchers frequently disagreeing about the nature of concept formation and change. This has led to a seemingly unsystematic approach to investigating conceptual development in science in comparison to the work in literacy and numeracy (Tolmie, 2012). Moreover, the work into literacy and numeracy has been unable to shed light onto the nature of conceptual development in science since the underpinning skills and effective pedagogical strategies involved in literacy and numeracy are both specific and distinct; hence there is clear implication that science requires separate systematic investigation. The organisation and the development of skills and concepts in various areas is simply too different, and research into the domain-specificity of conceptual development corroborates this (see Hirschfeld \& Gelman, 1994).

The difficultly is compounded by the fact that the nature of conceptual progression for any discipline (literacy, numeracy, science) is unknown and under-researched. There is some evidence to suggest that conceptual progression is unlikely to take such a sequential pathway as depicted by current curricula, but more likely to be fragmented with very little connection between ostensibly logically related phenomena. For instance Tolmie et al (2009) have shown that even within a single curricular topic such as physical state change, understanding of melting among 8-yearolds is not predictive of understanding of evaporation. If this research is taken as accurate, then no prior assumptions can be made about appropriate conceptual sequencing, before empirically demonstrating areas of connection. Indeed the extent to which there are associations between advancements in different areas of understanding, may simply reflect the operation of general cognitive mechanisms. It may be that progress in different areas is being driven to some extent by the same underlying capabilities (e.g. executive functions, attention etc) but within differing contexts, thus it is possible to have no connection in terms of content 
between different conceptual areas and yet still have similar and related levels of progress.

Consequently a systematic investigation is needed to assess how far any sources of shared variance between different conceptual areas are simply explicable in terms of general cognitive capabilities, as thus far studies have routinely failed to address this. Any variance that is not explained by these general cognitive capabilities, therefore, may then imply conceptual integration or progression of some kind which would be more informative for research, given the current nature of curricular sequencing.

\section{Naïve Biology}

One potential factor that increases the difficulty of understanding conceptual progression in science is the broad areas within science itself: chemistry, biology and physics. Each area deals with quite differentiated, complex concepts that are often highly theoretical in nature. Therefore it may be unhelpful to assume that conceptual progression in all scientific areas is likely to be the same, because the nature of conceptual growth might differ according to the types of phenomena involved. There has always been recognition of the complex systems involved in biology as the very nature of this discipline seeks to take smaller concepts and merge them together to understand various phenomena, unlike physics for instance where the emphasis is on deconstructing broad concepts into their fundamental principles. For these reasons a focus on biology might be initially productive because inherent relatedness between different contexts makes it a better area to look for connections between concepts and observe how these influence the growth and development of each other.

Much of the previous work within the domain of biology has focused on children's early or naive ideas about inheritance and has been taken to indicate that children have fairly coherent concepts by age 5 (Springer, 1999). There have been various theories offered to account for children's reasoning at such a young age but ideas around essentialism have been by far the most frequent. Essentialism has been used as a potential early precursor of genetic concepts, and refers to the idea that natural kinds contain 'essences' of their being which makes them what they are (Gel- 
Nuevos enfoques para comprender el desarrollo de los conceptos biológicos en niños pequeños

Zayba Ghazali y Andrew Tolmie

man, 2003). It is often the case that essentialist responses from children have been used as evidence of biological reasoning which in turn provides evidence for a domain of naïve biology (Carey, 1985; Altran \& Medin, 2001). However, there is increasing research to suggest that essentialist reasoning may be little more than reflecting children's cultural or behavioural knowledge in the absence of any biological causal or mechanistic understanding (Soloman, 2002). Often the language children use during investigations has been taken as evidence for essentialism, and evidence for domain-specific biological knowledge, yet the criteria used to interpret language as essentialist are abstract, and interpretations may therefore be erroneous.

For example Taylor (1996) examined children's essentialist beliefs about gender using a nature/nurture task. Children were given a story about an infant boy raised only by women and then asked to infer various properties about the same child when he was 10 years old. When asked whether the boy would play with a truck or a tea set, a boy aged 5 replied: "because boys play with boy things and girls play with girl things." in comparison to a boy aged 10 "because usually, since she has a girl brain, she'd like to play with a tea set." (See Gelman, 2003, p.97 for more examples). These examples demonstrate that although older children seem to be alluding to some kind of underlying mechanism for why girls like to play with tea sets, all the 5-year-old is doing is asserting an observable probability and no sense of mechanistic understanding is evident here at all. Despite this, examples such as these are common of the types of language children use that have been interpreted as evidence of essentialism when what really seems to be taking place is simply a demonstration of probabilistic understanding of biological phenomena.

Other paradigms used to test children's notions of essentialism often involve unrealistic and over-simplistic scenarios. Keil (1989) showed young children pictures of animals and told them about transformations doctors made altering the characteristics of these animals, such as a tiger having its fur bleached and a mane sewn on so that it resembled a lion. Children were then asked if the animal became a lion or was still a tiger and the findings showed that young children maintained that the animal's identity would not change. The results of such studies are taken as evidence for essentialism, and yet they may simply indicate children abiding by the rules of causal laws connecting category membership. Indeed a large body of research has demonstrated that children are na- 
turally good at categorisation from a very early age (Mareschal \& Quinn, 2001) and could explain why in the essentialist paradigm, children are able to understand the maintenance of identity. Hence by those same terms, the data used to infer essentialist reasoning, which in itself has uncertain characteristics, may be amenable to a simpler and more plausible interpretation. It may be that children are simply observing and recognising potent patterns available in their immediate environment. From this viewpoint, results may be demonstrating children's effort to capture the force of strong patterns of association that they have observed and a tendency to tacitly assume, without any particular mechanism being inferred, that these reflect causal laws connecting natural kinds and their observable properties. In support of this, recent studies have examined the extent to which young children's judgements conform to probabilistic models and found that children are quite capable of detecting patterns which lead them to infer causal relationships from the age of about 2 years. Schulz and colleagues (2007) looked at children's ability to learn causal structures from the outcome of a series of interventions using a novel toy. The study found pre-schoolers were accurately able to identify patterns of evidence from the interventions allowing them to learn the causal structure of events, and in turn allow them to predict the outcome of novel interventions. However the ability to detect patterns of regularity does not necessarily equate to a mechanistic understanding, even of a rudimentary kind.

Past research has all too often focused on children's understanding of interspecies variation, which is accentuated by the work around essentialism where the essence of an organism gives rise to observable similarities shared by members of the same category, allowing the child to understand that different species vary. However, the very nature of essentialism means children will assume members of a species are alike so by default should fail to understand variation of members within a species (Shtulman \& Shultz, 2008). Indeed it is exactly the idea of intraspecies diversity which research following the essentialist paradigm has ignored entirely. The differences between children's conceptual development between inter- and intra-species variations has scarcely been investigated, which is concerning given the obvious consequences around basic evolutionary ideas about successive adaptation.

It seems unreasonable to continue to investigate children's understanding of inheritance using paradigms that constrains their answers, but 
Nuevos enfoques para comprender el desarrollo de los conceptos biológicos en niños pequeños

Zayba Ghazali y Andrew Tolmie

more generally, also constrains progression in research. Up until now, much of the literature has been about confirming or disproving children's notions of essentialism and by doing so, research has failed to consider other dimensions behind the inheritance concept and its relationship with other ideas. Instead it seems appropriate to start an investigation into children's biological knowledge based on established research about what children are known to be capable of. Firstly it has been documented that children as young as six months have a strong tendency to detect the perceived relationships between events and to make probabilistic judgments about them, and even more evidence to suggest that this capability is generally established by around age two (Gopnik, Sobel, Schulz \& Glymour, 2001). Secondly, it has also been well documented that children have a natural tendency for categorisation with which meaningful language is also acquired (Gelman \& Coley, 1991). What this indicates then is that if the theoretical debates about inheritance and essentialism are put to one side, there seem to be two naturally occurring tendencies in children: perceptions of co-varying regularities, and categorisation.

Consequently what is needed to move forward is to begin research with these already established ideas and project what conceptual development might look like if these were the point of departure, mapping observations against this projection to see how far it is borne out, using a more natural methodology that nevertheless still pushes at the boundaries of what children are capable of understanding or saying. Providing children with more familiar contexts is also likely to give them some assistance with which to ground their ideas, rather than using more artificial constructs as in the past. In this way more in-depth analysis about children's conceptualisations should help uncover the developmental trajectory of conceptual progression in biology. Rather than focusing exclusively on inheritance, the natural extension would be to broaden the range of concepts to include ecology, biodiversity and evolution, since these all share a number of important points of connection and overlap heavily. These concepts in themselves are not unitary but are made-up of more important sub-elements and what is needed is a method of capturing children's understanding of all these elements in an even-handed fashion so that the relationships between them (and to more general cognitive capabilities) can be investigated.

This also has implications when considering the primary scien- 
ce curriculum in England. Inheritance, biodiversity and ecology are topics that are currently taught in the NC in KS1 and KS2 (with Evolution due to be included in 2014) and provide a logical set of ideas to explore the developmental path of concept formation based around inheritance which has already been fairly well established in the literature. These four concepts ${ }^{2}$ (inheritance, biodiversity, ecology and evolution) are explored in more detail in the Table below.

\section{Table 1. Deconstructing the biological concepts}

Biodiversity is a term used to describe the variety of life in the world or within a particular habitat or ecosystem. It is a less well articulated idea in the research in comparison to inheritance, and little is known about the possible routes of progression in biological concept development. The existence of this diversity is typically directly evident to children simply from observation of the world around them and thus implies perceptual registration as the start point in conceptual development. An established body of

Biodiversity research already implies children have a natural tendency to categorise and so taxonomy is likely to be grasped fairly early on in development. Of course biodiversity covers a broad range of subconcepts, but taxonomy and categorisation allow the recognition of differences in diversity in the environment and perpetuation of these differences. In this regard, biodiversity may be a potential start point for routes of conceptual progression in biology (because of the early categorisation tendencies of children) but nothing is yet known about the expected trajectories of developmental progression.

Ecology is the scientific study of interactions among and between organisms and their physical environments. The idea of interdependence is a key feature of the definition. This includes knowledge on the relationships between organisms but also the environment. Ecology is organised under many levels of interaction with individual sub-concepts that need to be linked in orEcology der to have a complete understanding. Thus ideas about ecology need to be fractionated into different elements because a young child is unlikely to have the cognitive capacity to deal with or to understand all of the components of this broad concept. By separating the large number of ecological sub-elements one is able to assess what kinds of concepts are understood when and what other types of knowledge will influence this.

2 Note that henceforth 'concepts' refers to only inheritance, biodiversity, ecology and evolution either collectively or individually. 
Nuevos enfoques para comprender el desarrollo de los conceptos biológicos en niños pequeños

Zayba Ghazali y Andrew Tolmie

Inheritance describes the passing of traits from parents to offspring and is the most studied area in biology. If children are acquiring perceptions of co-varying regularities in the environment and thus are gaining some implicit knowledge about particular biological phenomena, it may be that a young child may have no real sense

Inheritance of inheritance other than the patterns of observed regularity in the environment making it highly probable that organisms give birth to the same kind. The differences between children's conceptual development between inter- and intra-species variations has scarcely been investigated, which is concerning given the obvious consequences around basic evolutionary ideas about successive adaptation.

Evolution is the process by which different kinds of organisms are thought to have developed and diversified. Evolution covers a wide range of complex concepts but Shtulman and Shultz (2008) define two branches: micro-evolutionary concepts including inheritance, variation and adaptation, and macro-evolutionary concepts including speciation, domestication and extinction. It is certainly the case that knowledge about evolution would require prerequisite knowledge of inheritance, biodiversity and ecology

Evolution to be fully understood. An important distinction with evolutionary ideas appears to be the temporal dimension (Sander et al., 2006) which may make macro-evolutionary concepts harder to grasp.

There is virtually no research on development of evolutionary concepts among primary school children, presumably because any work conducted using the essentialist paradigm by default fails to consider aspects of intra-species variation which is a key element to understanding natural selection; the mechanism behind evolution.

\section{Routes of Progression}

By deconstructing the biological concepts in this way, it can be seen how simply from perceptual data that children might begin to understand key biological ideas. Designing a study that taps into the range of related concepts will make it possible to track the developmental trajectories of children throughout the primary age range. To clarify, the aim of the present research is not to discover what the end-point of knowledge might look like; rather it is to investigate the nature of concept formation and concept change within biology. There are a number of possibilities for conceptual progression, the implications of which are likely to vary. It 
may be that children have theoretical knowledge from an early age and acquire particular key concepts which link to other peripheral concepts, so that early key concepts in one area may help to provide a basic foundation for other connected ideas to eventually form a coherent body of interconnected knowledge, and thus is compatible with current curricular sequencing.

Alternatively, it may be that there is only a limited degree of co-ordination within particular areas which do not inform each other too well. The exposure children have to various biological phenomena through different means (school, zoo trips, media etc) and children's natural tendencies to perceive regularity and categorise, may give rise to an experiential sequence which is likely to vary cross-culturally. The ideas may be somewhat isolated from each other in development and only inform each other at a basic level, at least to begin with.

On the other hand, knowledge may remain context-specific throughout with the child piecing streams of information together as their cognitive capabilities permit. Layers of knowledge are acquired gradually and thoughts are not integrated even at the level of topic. This route may also explain the fragmented picture research often depicts around children's early biological knowledge.

These potential routes vary in the way that knowledge is acquired and used by children. As such, each route would lead to contrasting developmental patterns in terms of both growth of understanding and the relationship between different elements.

\section{Domain-General (DG) capabilities}

If children are capable of observing potent patterns within a highly regular environment, one would assume some inherent ability or existing mechanisms are already in place to be able to capture this degree of regularity. This intrinsically forms the foundation of learning or cognition and highlights the importance of investigating DG capabilities in children. Indeed the extent to which there are points of connection between different biological areas could be driven in part by underlying DG capabilities.

Many studies have considered the effect of executive function and language ability on academic achievement (Gathercole et al., 2003; 
Nuevos enfoques para comprender el desarrollo de los conceptos biológicos en niños pequeños

Zayba Ghazali y Andrew Tolmie

Alloway et al., 2008) and there are some indications that working memory (WM) and executive functions might well be implicated in science learning in preschool (Nayfield, Fuccillo \& Greenfield, 2013). However research has regularly failed to account for science learning and achievement throughout primary school and as a result, little is known about the exact effects of DG capabilities on science learning. Although there has been work to suggest number ability and science ability are connected in terms of relative rates of progress (Gathercole et al., 2004; St ClaireThomas \& Gathercole, 2006), the exact nature of this relationship has not been examined in great detail and it is possible that the mediating role of language may also account for this.

Research does point towards the likelihood of a relationship between DG capabilities and science learning, in that gaining explicit knowledge is likely to occur through verbally formulating explanations. In this sense language might be a key predictor of academic performance. Therefore it seems important to investigate language in order to assess how far any sources of shared variance between different conceptual areas are simply explicable in terms of general cognitive capabilities.

\section{Methodological Development}

The aim of this research is to track conceptual progression of biological concepts across primary school children aged 4-11 using an accelerated longitudinal design. The following section describes pilot work undertaken after the development of a novel methodology and the results of this work. The ultimate aim of this pilot study is to use this new approach in testing children's biological knowledge in the longitudinal study in order to investigate the progressive conceptual changes and any group differences in these changes, and to assess how some biological concepts influence the development of others.

\section{Design}

A task was developed for the present study based on an earlier one used by Hipkins and colleagues (2008) adapted for use among children across the primary age range (4-11years). Children were presented with an A3 sized drawing of two contextual scenes: a savannah 
and a pond, and were interviewed about their biological knowledge based around these two exemplars. These particular scenes were chosen based on earlier pilot work which suggested children (aged 4-11) had most knowledge about and could readily discuss with ease. Each context provided children with assistance in framing their ideas around the particular narrative that was presented but would also highlight the differences in knowledge acquisition and integration between varying contexts (Almeida et al., 2013). Children were then interviewed in a semi-structured format about various aspects of the four biological phenomena: inheritance, biodiversity, ecology and evolution. Within each contextual scene, four different kinds of animals were also drawn to allow children to interact with the task and place the organisms on to the scene. This facilitated discussion around biological entities and relationships, but also engaged the child and aided interpretation of the interview questions. The contexts and their criteria for selection are displayed in Table 2, alongside the animals used. It was also necessary to be sure that the children were familiar with the animals selected, but also that the food chains were accurately depicted in the scene. For this reason Age of Acquisition indices (Kuperman, Stradthagen-Gonzalez \& Brysbaert, 2012) were consulted to see when children acquire the vocabulary to describe a particular animal on average and the animals were selected on this basis so that each scene was as closely matched as possible.

Table 2. Illustrating the contexts used and their selection criteria $\&$ age of word acquisition

\begin{tabular}{lllc}
\hline Context & Key criteria for selection & $\begin{array}{l}\text { Animals } \\
\text { used }\end{array}$ & $\begin{array}{l}\text { Average age chil- } \\
\text { dren acquire word }\end{array}$ \\
\hline Lake & Replication of Hipkins et al (2008) & Frog & 4.32 \\
& where a lake was used. A lake is an & Trout & 8.56 \\
& obviously constrained environment & Heron & 10.35 \\
& with regards to the types of organisms & Otter & 5.47 \\
& one would expect to find there & & \\
\hline \multirow{2}{*}{ Savannahh } & A more loosely constrained envi- & Lion & 4.42 \\
& ronment, one that children are less & Cheetah & 8.16 \\
& familiar with in terms of physical ex- & Gazelle & 9.37 \\
& perience however are often exposed & Zebra & 4.79 \\
& & & \\
\hline
\end{tabular}


Nuevos enfoques para comprender el desarrollo de los conceptos biológicos en niños pequeños

Zayba Ghazali y Andrew Tolmie

The development of the interview schedule was grounded in the current content of the NC. The curriculum specifies many aspects of the four biological concepts that have been broken down into smaller elements that could be taught across the primary years sequentially. For example, under inheritance for KS1: children must recognise that animals produce offspring that grow into adults. This gets developed in KS2: children must recognise life processes common to animals including growth and reproduction (DfE, 2011).

Every element of the science curriculum that related to any of the four biological concepts (inheritance, biodiversity, ecology and evolution) was used to identify elements of core knowledge for each concept, which when taken together allows (theoretically) for a full and coherent understanding of that broader concept. Core knowledge refers to the key ideas about a particular concept a child is required to know in order to grasp that particular concept. This serves as a useful structure on which to focus, both in terms of obtaining an overall picture of primary children's understanding and how far it equates with curricular objectives at different ages. Thus a question was developed to specificaIly address each element of core knowledge. Despite the weaknesses of curricular assumptions about conceptual progression, it is nevertheless the case that a serious attempt has been made to break different key areas down into definable components based on current science. For example science learning is fractionated into broad headings such as life processes and living things, and based on earlier predefined terms, each element of knowledge under this banner was allocated to one of the four key biological concepts. For instance: "recognise similarities and differences between themselves and others" (DfE, 2011) was identified as an element of biodiversity knowledge as it emphasises the differences and similarities between and within species. Many of the areas in the current and proposed curriculum were not very specific, and often one element would refer to humans, animals and plants, for example "group living things into observable similarities and differences" (DfE, 2011). In cases like these, the element was divided into even smaller parts relating to humans, animals, and plants ${ }^{3}$ so that individual elements could be investigated in as much detail as possible. The objective was to provide a more refined set of questions to ensure each element of core knowledge had actually been targeted.

3 Note that the curriculum refers to humans and animals as separate, so corresponding terms have been used here. 
In total a set of 35 questions were developed and were sequenced in a logical order. Firstly questions about the animal survival and habitat on the task were asked followed by similar questions around plant survival and habitat (e.g. why can't a lion live in really cold weather but a polar bear can?). These were followed by growth and inheritance questions about animals, plants and humans (e.g. Do you think all zebras look exactly the same?). Finally questions about competition, taxonomy and ecosystems (e.g. If lions eat zebras, how come there are still lots of zebras around in the savannah?) were followed by questions around adaptation, fitness and natural selection (e.g. Zebras are good at hiding so lions can't catch them. The ones with lots of stripes are really good at hiding. This lion is hungry, which of these zebras [varying stripes] do you think it is likely to catch first?). All responses to questions were probed to expose the reasoning children used to reach their answers.

\section{Procedure}

The sample ( $\mathrm{N}=18)$ for this pilot study was recruited from one North London primary school. There was an equal number of boys and girls. Six children were selected from Years One (age5-6), Three (age7-8) and Five (age9-10) to provide an overview of children's understanding at various ages. Testing was conducted over three consecutive days and each child was interviewed individually in a quiet room for approximately 35 minutes. Children were informed about what they had to do and were given the opportunity to ask questions. Informed parental consent was obtained as well as verbal consent from each child prior to testing. Children were told they had the right to withdraw at any time.

Children were shown one A3 scene after the other (counter-balanced) and asked questions about each one in turn. All interviews were audio recorded and later transcribed.

Children were first questioned on their comprehension about aspects of the context as it was important to check that they could identify the context and the animals within it. This was possible even when they did not have the correct vocabulary, for example, savannah is a word that primary school children may not have encountered before, therefore "safari" or "Africa" were among the terms also accepted following further probing. All children were able to correctly identify the scenes and so proceeded to the interview phase. 
Nuevos enfoques para comprender el desarrollo de los conceptos biológicos en niños pequeños

Zayba Ghazali y Andrew Tolmie

\section{Scoring}

A coding scheme was developed based on the same core knowledge structures. A content analysis was conducted after transcribing interviews, and key features were used to define different levels of understanding and these were allocated scores between 0-7 where a higher score meant more sophisticated conceptual knowledge. For example, an answer such as "I don't know" was given a score of 0 , but a response such as "because...something will happen" is given a score of 1 as this response is a non-exploratory simple assertion, yet the child has identified that a consequence is likely to occur. Answers to some questions using non-biological reasoning were given a lower score than using biological reasoning, and even higher scores if scientific vocabulary was used. For instance in answer to the question "what will happen to the zebras if there were no more lions?" a response such as "they will be sad because the lions are their friends" would be given a score of 2 as the child has identified it would be a problem for the zebras, yet the reasoning for this is not biological. In contrast, a response such as "it will make a big difference because the lions aren't there and the zebras can populate more, but if it's for a long time then that's worse and the lion needs to come back" would be given a score of 4 as the child has identified ideas around food chains and has used biological causal reasoning over non-biological reasoning. Likewise as children begin to correctly explain causal mechanisms behind their answers, their scores for that particular question increases. The present study therefore coded interview answers on the basis of how much core knowledge a child had about particular biological concepts; the coding generated an ordinal score and such scores were derived for each element of core knowledge and these were then totalled. Hence a score for each biological concept was derived from scoring individual core knowledge elements. Finally each environmental context also received a separate score to see the extent children's knowledge was context-specific.

\section{Findings \& discussion}

As this is a pilot study, no concrete claims are made about the data. Instead general findings and patterns are discussed. Firstly, children showed little evidence of essentialism. The data revealed children's early ideas about 
inheritance seemed to be fairly fragmented and there was no evidence of essentialist beliefs in contrast to findings obtained from previous work. Indeed very few children were knowledgeable on this area and often displayed piecemeal knowledge about all concepts rather than a coherent representation of a particular biological phenomenon. Generally there was no evidence of coherent ideas about any biological concept, even among the older children. Previous work has often depicted inheritance as the starting point for biological conceptual development, yet this work suggested biodiversity was instead. Indeed taxonomy, a principal feature of biodiversity, is inherent in young children's everyday interactions. Children regularly label and categorise things they encounter, even during formal instruction, which is possibly why concepts about biodiversity seemingly emerge before other biological concepts. As expected, ecological and evolutionary concepts were much less understood, possibly be due to a lack of diachronic thinking ability (Maurice-Neville \& Montangero, 1992) as principally, these concepts need to be grasped with regards to change across a temporal axis. It may be a primary school child's inability to do this which makes ecological and evolutionary concepts much harder to comprehend in any coherent fashion.

Interestingly, children demonstrated differences in reasoning with age. The key areas missing from children's knowledge seemed to be ideas around causal process and mechanisms behind biological phenomena, and reasons why things were as they were. Often young children wildly guessed the answers to questions addressing their understanding of mechanisms. It was only towards year 5 that some children were able to offer logical and partially correct answers. This suggests that children's early knowledge may not be theoretical, but perhaps more perceptual in nature. The pilot study also revealed a change in the causal reasoning children used with age. Many of the explanations behind children's ideas in year 1 were attributable to more psychological or teleological reasoning, rather than mechanistic or biological causal explanations offered by children in year 5 . For example, when children were asked what the effect would be if the pond dried out, a boy aged 6 replied: "people would come and get water in their buckets." In contrast, a boy aged 10 replied "if it doesn't rain for a while then the most of the animals will die, some might go to another pond", thus demonstrating key differences in their reasoning. A key turning point for social to biological causal reasoning seemed to be around age $7 / 8$ where children preferred 
Nuevos enfoques para comprender el desarrollo de los conceptos biológicos en niños pequeños

Zayba Ghazali y Andrew Tolmie

biological explanations over social ones. However despite this, some social reasoning was still offered even among the older children aged 10 suggesting when biological causal explanations were unknown, nonbiological explanations were offered to aid understanding. This is further supported by the fact that media and prior experience seemed to heavily influence children's knowledge. Hence rather than a domain of biology emerging out of a domain of psychology, as argued by Carey (1985), it may simply be the case that the domain of biology changes over time with the acquisition of more biological knowledge, which incidentally may still be classed as 'naïve' by the end of primary school. In any case, this effect would be consistent with the absence of evidence in favour of essentialism, which has previously been used as a marker for a child to move from a domain of psychology to a domain of biology.

When linking the findings back to the theoretical research, there was some evidence that a lack of appropriate language, scientific or otherwise, was a hindrance for many of the young children when it came to explaining their ideas. This of course is to be expected given the age-range, however what was apparent was that there did seem to be some evidence of a dichotomy between implicit and explicit knowledge. Work by Howe (2012) explores this a little further and considers that tacit knowledge may exist in children which can sometimes contradict their explicit beliefs. It seems that children's natural tendency to assess the patterns of regularity in the environment around them is the trigger for subsequent conceptual change and future conceptual development. It is likely that this forms the basis of implicit thinking and through the later development of language and DG capabilities, develop into explicit thought and reasoning about biological phenomena. This may be directly reflecting the development of executive function and attentional control. This is important to explore because it might be that DG functions need to be assessed in order to understand the potential sources of individual variability.

Observation seems to play a significant role in the development of biological concepts, but there do seem to be different types of observation which have different outcomes on children's ideas. Firstly children were likely to have more coherent knowledge based on their direct tacit observation and experience of their environment around them. In one instance, a child had immense knowledge about pond life due to regular fishing trips however this was context-specific and knowledge was not 
generalised to the context of a savannah. Secondly, children had more knowledge around ideas about the savannah and yet none had visited the place before. This highlights the role of media and observation directed by narrative as a possible primary resource of knowledge for children. However, while narratives may help explicit knowledge construction, especially when these narratives are repeated, they often create biased or distorted ideas as a result because the ideas do not correspond to more accurate 'objectively' available data through direct tacit observation. These ideas will need to be investigated in more detail in the main experiment, therefore.

\section{Design of planned longitudinal study}

As a method to assess biological concepts has now been developed and tested, the phases of the longitudinal research can be considered because the main overarching aim of this research to map out a developmental trajectory relating to biological knowledge across children aged 4-11 years and to investigate factors which contribute to, or may be predictive of this biological knowledge. An accelerated longitudinal design will be used whereby children will be 'matched' across three different age cohorts based on values of demographic and standardised DG capability measures described below, with a child aged 4 being linked to a child aged 7 and another aged 10 with a similar demographic profile and percentile position on the cognitive indices. The three cohorts are shown below, broken down by age at two planned phases of data collection. Note that the groups in phase 2 are the same as those in phase 1 , one year later.

\begin{tabular}{lll}
\hline & Age & Year at School \\
\hline \multirow{3}{*}{ Phase 1} & $4 / 5$ & Reception \\
& $6 / 7$ & Year 2 \\
& $9 / 10$ & Year 5 \\
\hline \multirow{3}{*}{ Phase 2} & $5 / 6$ & Year 1 \\
& $7 / 8$ & Year 3 \\
& $10 / 11$ & Year 6 \\
\hline
\end{tabular}

Table 1 
Nuevos enfoques para comprender el desarrollo de los conceptos biológicos en niños pequeños

Zayba Ghazali y Andrew Tolmie

Demographic measures will be only obtained for the children during Phase 1 and will include measures of: socio-economic status, home learning environment, home language and preschool attendance. Details about parental levels of education, occupations and siblings will also be obtained.

Measures of DG capacities will be collected during both phases so that their concurrent and lagged predictive values can be examined. These measures target executive functions and short-term memory (specifically verbal, visual and working memory) which have previously been implicated in science learning in secondary school, but whose predictive values in primary school have never been explored. A measure of receptive language and numeracy will also be administered in order to investigate the relationships between language and numeracy with science learning in primary school. It is hoped that through this design a clearer picture about conceptual development in primary biological education can be obtained providing valuable information for educational enhancement and remediation as a course for future studies.

\section{References}

Alloway, T. P., Gathercole, S. E., Willis, C., \& Adams, A.-M. (2004). A structural analysis of working memory and related cognitive skills in young children. Journal of Experimental Child Psychology, 87(2), 85-106. doi:10.1016/j.jecp.2003.10.002

Almeida, A., Vasconcelos, C. M., Strecht-Ribeiro, O., \& Torres, J. (2013). Non-anthropocentric Reasoning in Children: Its incidence when they are confronted with ecological dilemmas. International Journal of Science Education, 35(2), 312-334. doi:10.10 80/09500693.2011.608387

Altran, S. Medin, L. et al. (2001). Folkbiology doesn't come from folk psychology. Journal of Cognition and culture, 1(1), 3-42.

Carey, S. (1985). Conceptual Change in Childhood. Massachusetts: MIT Press.

Darwin, C. (1859). On the Origin of Species. (W. Bynum, Ed.) (2nd ed., pp. 1-479). London: Penguin Classics.

Department for Education and Employment. (2011). The National Curriculum Handbook for Primary Teachers in England Key Stages 1 and 2. London: The Stationery Office.

Driver, R., Guesne, E., \& Tiberghien, A. (Eds.). (1985). Children's ideas in Science (pp. 1-202). Milton Keynes: Open University Press.

Dowker, A., \& Sigley, G. (2010). 'Targeted interventions for children with arithmetical difficulties'. In R. Cowan, M. Saxton and A. Tolmie 9eds), British Journal of Educational Psychology Monograph Series II: Psychological Aspects of Education - Current Trends: No.7. Number Development and Difficulty. Leicester: BPS. 
Nuevos enfoques para comprender el desarrollo de los conceptos biológicos en niños

pequeños

Zayba Ghazali y Andrew Tolmie

Gathercole, S. E., Brown, L., \& Pickering, S. J. (2003). Working memory assessments at school entry as longitudinal predictors of National Curruculum attainment levels. Educational and Child Psychology, 20(3), 109-122.

Gathercole, S., Pickering, S., Knight, C., \& stegmann, Z. (2004). Wokring memory skills and educational attainment: evidence rom national curriculum assessmetns at 7 and 14 years of age. Applied Cognitive Psychology, 18,1, 1-16.

Gelman, S.A., \& Coley, J.D. (1991). Language and categorization: The acquisition of natural kinds terms. In S. Gelman, S.E Byrnes, and P. James (eds.) Perspectives on Language and Thought: Interrelations in Development. New York: Cambridge University Press.

Gelman, S. A., \& Hirschfeld, L. A. (1999). How Biological is Essentialism? In S. Altran \& D. Medin (Eds.), Folk Biology (p. chapter 12). Cambridge, Massachusetts, USA: MIT.

Gelman, S.A. (2003). The Essential Child: Origins of Essentialism in Everyday Thought. Oxford Series in Cognitive Development. Oxford, UK: Oxford University Press.

Gopnik, A., Sobel, D. M., Schulz, L. E., \& Glymour, C. (2001). Causal learning mechanisms in very young children: Two-, three-, and four-year-olds infer causal relations from patterns of variation and covariation. Developmental Psychology, 37(5), 620 629. doi:10.1037//0012-1649.37.5.620

Gopnik, A. \& Welman, H (1994). The 'theory theory'. In S.A Gelman \& L.A Hirshfeld (1994). Mapping the Mind: Domain Specificity in Cognition and Culture. UK: Cambridge Univeristy Press.

Hipkins, R., Bull, A., \& Joyce, C. (2008). The interplay of context and concepts in primary school children's systems thinkingT. Journal of Biological Education, 42(2), 73-77. do i:10.1080/00219266.2008.9656114

Howe, C., Tavares, J., \& Devine, A. (2012). Everyday conceptions of object fall: Eplicit and tacit understanding during middle childhood. Journal of Experimental Child Psychology, 111, 351-366.

Hulme, C., \& Snowling, M.J. (2009). Developmental Disorders of Lnaguage Learning and Cognition. Chichester: Wiley-Blackwell.

Keil, F (1989). Concepts, kinds, and cognitive development. Cambridge, MA: MIT Press.

Kuperman, V., Stadthagen-Gonzalez, H., \& Brysbaert, M. (2012). Age-of-acquisition ratings for 30,000 English words. Behavioural Reseach, 44, 978-990.

Mareschal, D., \& Quinn, P.C., \& Lea, S.E.G. (2010). The making of human concepts. Oxford: Oxford University Press.

Maurice-Naville, D., \& Montangero, J. (1992). The development of diachronic thinking: 8-12-year-old children's understanding of the evolution of forest disease. British Journal of Developmental Psychology, 10(4), 365-383. doi:10.1111/j.2044-835X.1992.tb00583.x

Nayfeld, I., Fuccillo, J., \& Greenfield, D. B. (2013). Executive functions in early learning: Extending the relationship between executive functions and school readiness to science. Learning and Individual Differences, 26, 81-88. doi:10.1016/j.lindif.2013.04.011

Piaget, J. (1972). The Principles of Genetic Epistemology. New York: Basic Books.

Sander, E., Jelemenská, P., \& Kattmann, U. (2006). Towards a better understanding of ecology. Journal of Biological Education, 40(3), 119-123. doi:10.1080/00219266.2 006.9656028 
Nuevos enfoques para comprender el desarrollo de los conceptos biológicos en niños pequeños

Zayba Ghazali y Andrew Tolmie

Schulz, L. E., Gopnik, A., \& Glymour, C. (2007). Preschool children learn about causal structure from conditional interventions. Developmental science, 10(3), 322-32. doi:10.1111/j.1467-7687.2007.00587.x

Shtulman, A., \& Schulz, L. (2008). The relation between essentialist beliefs and evolutionary reasoning. Cognitive Science, 32(6), 1049-1062.

Solomon, G. E. A. (2002). Birth, kind and naïve biology. Developmental Science, 5(2), 213-218. doi:10.1111/1467-7687.00223

Springer, K. (1999). Acquiring a Theory of Biology. In M. Siegal \& C. . Peterson (Eds.), Children's Understanding of Biology and Health (pp. 45-70). Cambridge, UK: Cambridge University Press.

StClair-Thompson, H. L., \& Gathercole, S. E. (2006). Executive functions and achievements in school: Shifting, updating, inhibition, and working memory. Quarterly journal of experimental psychology (2006), 59(4), 745-59. doi:10.1080/17470210500162854

Strevens, M. (2000). The essentialist aspect of naive theories. Cognition, 74, 149-175.

Taylor, A. (1996). Children's conceptions of nature/nurture. In S.A Gelman (2000). The Essential Child: Origins of Essentialism in Everyday Thought. Oxford series in cognitive development. Oxford, UK: Oxford Univeristy Press.

Tolmie, A., Tenenbaum, H., \& Pino-Pasternak, D. (2009). Generalization in children's science explanations. European Association for research into Learning and Instrcution Biennial Conference, Amsterdam.

Tolmie, A. (2012). Understanding core skills and influences in primary school science learning: taking a scientific approach. London: IOE Press. 